\title{
Unusual Aspects of the Venom Apparatus of the Blue Coral Snake, Maticora bivirgata
}

\author{
P. GOPALAKRISHNAKONE ${ }^{1}$ and E. KOCHVA ${ }^{2}$ \\ Department of Anatomy ${ }^{1}$, Faculty of Medicine, National University of Singapore, Singapore; and Department of Zoology ${ }^{2}$, \\ Tel Aviv University, Israel
}

Received November, 6, 1989

\begin{abstract}
Summary. Light and transmission electron microscopic observations of the venom gland of the blue coral snake revealed a main venom gland and a long duct. The main secretory cell showed characteristic features of a protein secreting cell, with small microvilli, and a cytoplasm containing vacuoles and vesicles. Another type of "dark cell" and a third type of "basal cell" were also seen. "Nerve terminals" supplying the gland showed pleomorphic vesicles. The compressor muscle surrounding the venom gland showed the $A$ band, $Z$ disc, and $H$ zone. Satellite cells were seen among muscle fibres. The neuromuscular junctions supplying the muscle showed clear vesicles. Scanning electron microscopy of the fangs showed the entrance lumen, discharge orifice, suture and the dental ridge. These findings are compared with relevant structures in other snake species.
\end{abstract}

The structure of the snake venom gland has been studied extensively (see reviews by BDOLAH, 1979; KochVA, 1978a, b, 1987) mainly in the Viperidae and Elapidae (GENNARO et al., 1960; GANS and KochVA, 1965; KochVA and GANS, 1965, 1966, 1967; BENSHAUL, et al., 1971; GOPALAKRISHNAKONE and JAYATILAKA, 1978; KOCHVA, 1978a, b; JAYATILAKA and GOPALAKRISHNAKONE, 1981; GOPALAKRISHNAKONE, 1985a, 1986). There have also been some studies on the venom glands of sea snakes (Hydrophidae) (BURNS and PICKWELl, 1972; GoPALAKRISHNAKONE, 1985b). Apart from these studies, there were a few studies on the unusual, extended venom glands of the Israel Mole viper Atractaspis engaddensis (Ko. CHVA, 1959; KochVA et al., 1967). Since coral snakes from South East Asia also possess extended venom glands, it was decided to study in detail the structure and organization of the venom apparatus of the blue coral snake, Maticora bivirgata.
A previous study on the venom gland of the banded coral snake, Maticora intestinalis has been reported on briefly (GOPALAKRISHNAKONE, 1986).

\section{MATERIALS AND METHODS}

Coral snakes were collected from the wild. They were used for light microscopy, scanning electron microscopy and transmission electron microscopy. Some snakes were milked and sacrificed after a variable period. For light microscopy, the snakes were anaesthetized with ether and perfused with $10 \%$ formol saline. Following the perfusion, the whole venom gland with the surrounding muscle was dissected and longitudinal and transverse serial sections were made. The sections were stained with hematoxylin eosin, PAS and Masson's trichrome stain.

For transmission electron microscopy, the snakes were perfused with $2 \%$ paraformaldehyde and $3 \%$ glutaraldehyde in cacodylate buffer at pH 7.3 and post-fixed in osmium tetroxide. Sections were taken from various regions of the gland and embedded in Araldite. One micron thick sections were cut and stained with toluidine blue and used for light microscopy. Ultrathin sections were cut and stained with uranyl acetate and lead citrate, mounted on a copper grid and viewed under a Philips $400 \mathrm{~T}$ electron microscope.

For scanning electron microscopy, the snakes were perfused as for transmission electron microscopy. The fangs were cleaned using $1 \% \mathrm{H}_{2} \mathrm{O}_{2}$. The specimens were critical point-dried, mounted on aluminium stubs with silver paint and sputter-coated with gold for $3 \mathrm{~min}$. They were examined in a Philips 505 scanning electron microscope operated between 10 and $25 \mathrm{kV}$. 


\section{OBSERVATIONS}

\section{Gross anatomy}

The venom gland extended from the fang along the sides of the skull into the body cavity, measuring about $1 / 3-1 / 4$ of the body length. The right gland was shorter than the left one. Two portions of the gland could be distinguished: the duct, which included the anterior $2 / 3-3 / 4$ of the gland was narrow, cylindrical and elongated, marking the duct region; and the main venom which included the posterior $1 / 3-1 / 4$ region of the main gland, which was wider and firmer, saccular in comparison and conical in shape. Blood vessels ran on either side of the venom gland; they started to accompany the duct when closer to the fang and traveled up to the posterior part of the gland. There was no visible connective tissue attachment from the gland to the surrouning structures.

\section{Light microscopy}

The long tubular gland could be divided into three regions (Fig. 1): the main posterior secretory portion; the anterior slender conducting portion; and the intermediate or transitional zone. The gland showed a well demarcated capsule. Surrounding the capsule was the compressor muscle of the gland. The muscle reached up to the transitional zone, but did not extend into the duct region. All the muscle fibres were arranged along the longitudinal axis of the gland. The muscle fibres appeared to encircle the entire gland (Figs. 2, 4). There were no separate fasicles or bundles in the muscle. Blood vessels and nerve bundles were seen between the muscle fibres (Fig. 2).

The main venom gland consisted of secretory tubules which contained a single columnar epithelium with a prominent round nuclei situated closer to the base (Fig. 3). The cells were usually of uniform length and width. In some sections, basal cells were seen in addition to fibroblasts.

The fibrous capsule was well developed and organized around the gland. Delicate septa were seen extending from the capsule into the secretory tubules. In the main venom gland there were a few PAS positive cells scattered between the other secretory cells. The general arrangement of the gland appeared to be compound tubular. Large blood vessels were seen in association with the glands. They were seen running in a longitudinal direction even inside the capsule of the gland. The main venom gland tapered into a long, thin, narrow conducting portion or the duct. At the transitional zone, the duct appeared convoluted and covered by a very thin layer of muscles. The rest of the duct appeared as a single duct without any convolution and without any muscular covering (Figs. 5, 6). One section prepared from EM specimens stained with tuoluidine blue, showed both dark and light staining cells. There was no definite central lumen in the main gland. The duct was seen accompanied by large blood vessels on either side. The epithelium of the duct was simple cuboidal.

\section{Transmission electron microscopy}

The secretory epithelium of the main venom gland was either cuboidal or columnar depending on the activity of the gland. The nuclei were situated closer to the base (Fig. 7). The free border from the secretory border of the cells showed small finger-like microvilli. The cells showed typical features of a protein secreting cell, such as a well developed Golgi apparatus, a large amount of rough endoplasmic reticulum and abundant mitochondria, vacuoles and vesicles of various sizes and shapes, seen scattered in the cytoplasm. Few electron dense granules were seen in the cytoplasm or in the vicinity of the Golgi apparatus. Membrane bound vacuoles sometimes showed electron dense granules inside the lumen of the vacuoles. Granular secretion and membrane bound vesicles were seen outside the secretory border in the lumen. Between two secretory cells were seen cell junctions that sometime appeared to stain darker under EM. The basement membrane underneath the bases of the cells was covered by connective tissue, mainly collagen fibres. In between the secretory cells there were a few darkly stained cells, whose entire cytoplasm appeared electron dense in comparison to the neighbouring cells (Fig. 8). These cells also had their nuclei closer to the base. They also had a well-developed Golgi apparatus and rough endoplasmic reticulum (Fig. 9).

A third type of cell, which coull be referred to as a basal cell, (Fig. 10) was also seen. These cells were wedged between the bases of the adjoining secretory cells, appearing sometimes as triangular or oval cells. They were usually close to the base and covered by the same basement membrane, and did not extend into the lumen of the gland. These cells had large nuclei with well defined nuclear membranes. The cytoplasm contained few mitochondria and a Golgi apparatus. There no secretory granules seen in the cytoplasm. There were extensive interdigitations between this cell and the secretory cells. Numerous 
Fig. 1. Gross dissection thowing the venom glands $(G)$ and the duct $(D)$. Note the length of the gland is about half the length of the body.

Fig. 2. A section through the posterior part of the venom gland showing how the compressor muscle fibers are attached to the gland, as well as the arrangement of the tubules. $\times 45$

Fig. 3. Higher magnification of the secretory epithelium of the venom gland showing the arrangement of the tall columnar epithelial cells. $\times 280$

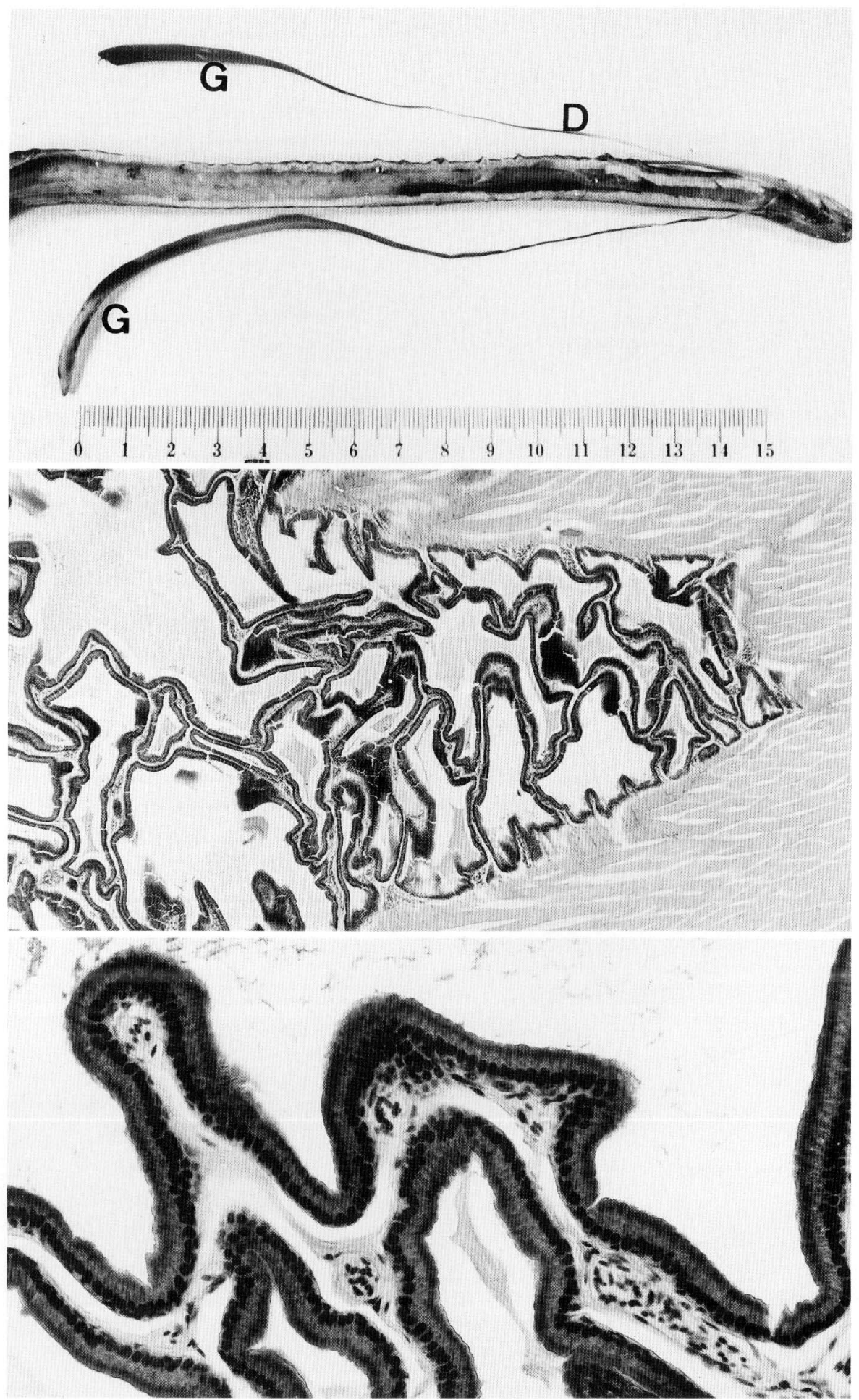



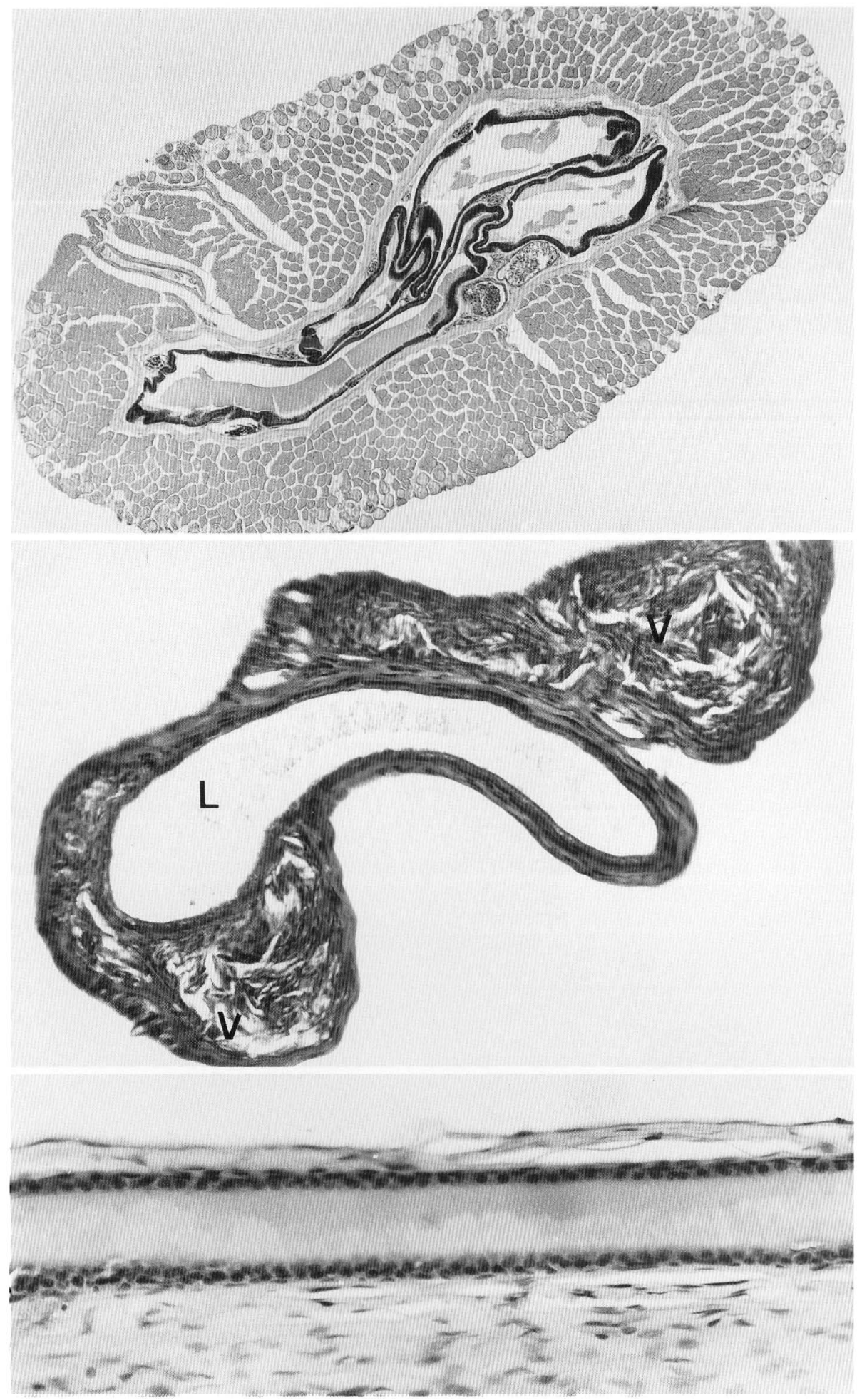

Fig. 4. A low power view of a transverse section of the venom gland showing the lumen and secretory epithelium surrounded by a capsule, which in turn is surrounded by a thick layer of muscle fibers. $\times 45$

Fig. 5. A transverse section through the duct, showing the lumen $(L)$ and on either side blood vessels $(V)$. Note how the lumen of the duct is lined by a simple flattened epithelium. $\times 280$

Fig. 6. A longitudinal section through the duct, showing the flattened epithelium lining the lumen and connective tissue surrounding the duct. $\times 10$ 
Fig. 7. Low power electron micrograph of the secretory epithelium of the blue coral snake venom gland. Two rows of simple columnar epithelia are situated in a basement membrane, face each other and are interposed by collagen fibres and connective tissue elements. The nuclei are situated closer to the base. The free border shows very small microvilli. $\times 39,900$

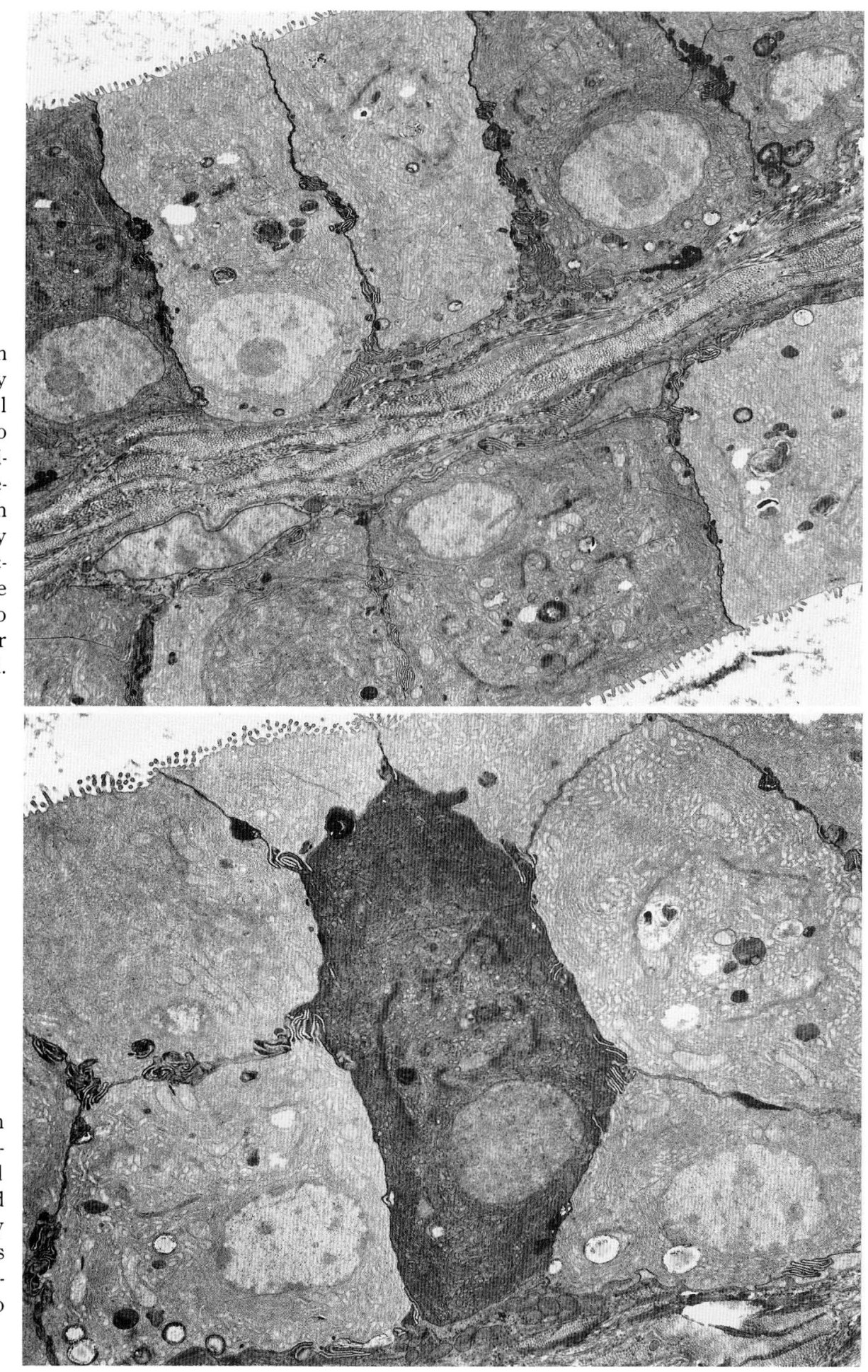

Fig. 8. An oblique section through the secretory epithelium of the venom gland showing a "dark" cell situated among the normal secretory cells. The cytoplasm stains very dark and the Golgi apparatus and the rER also appear darkly stained. $\times 5,000$ 

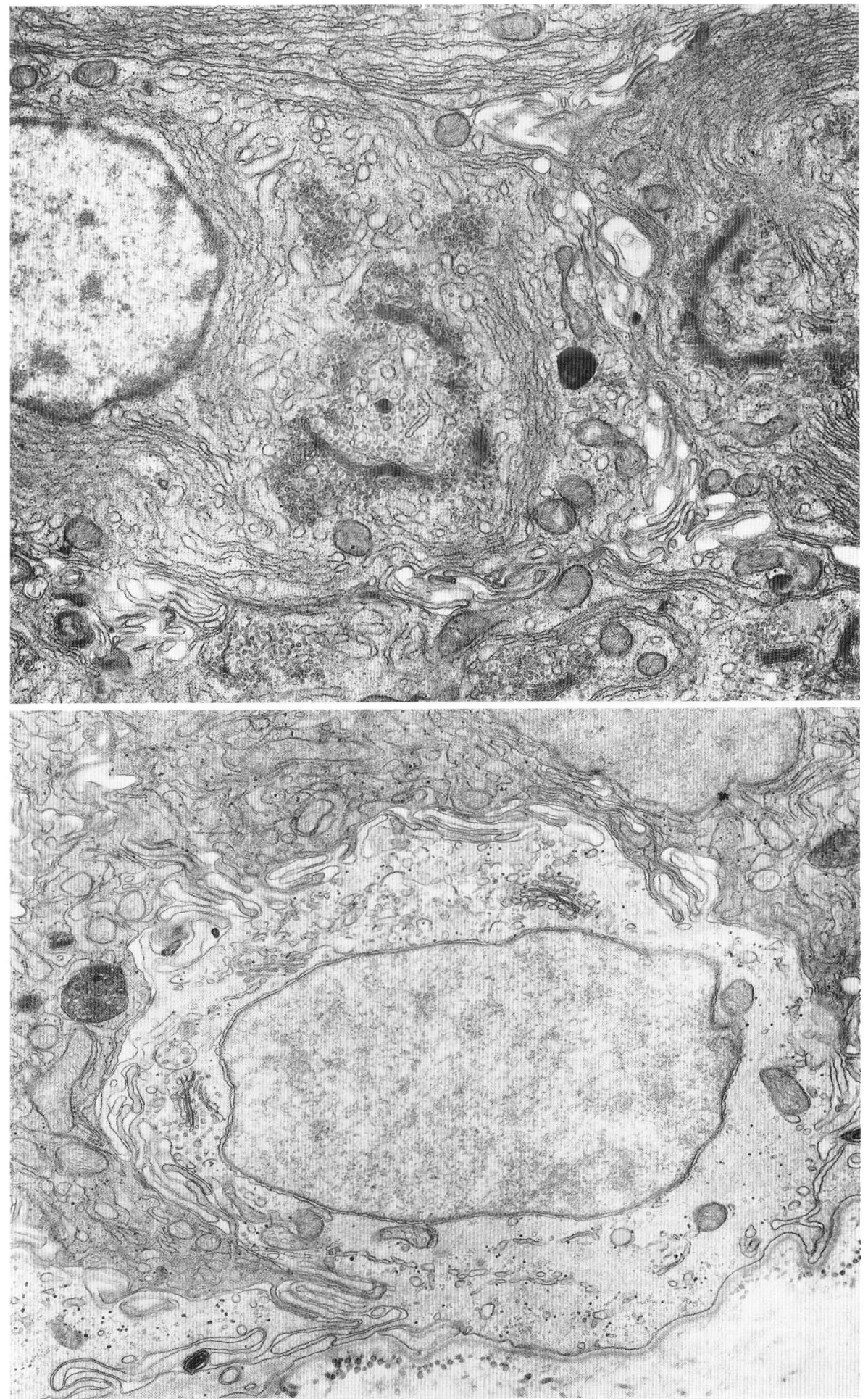

Fig. 9. Higher magnification of a cell showing the Golgi apparatus, rough endoplasmic reticulum, and vesicles in relation to the mature and immature faces. $\times 14,000$

Fig. 10. Higher magnification of a basal cell showing a large and prominent nucleus. The cytoplasm shows a Golgi apparatus, vesicles tubular cisterns and mitochondria; filaments also can be observed. $\times 14,000$ 
Fig. 11. Electron micrograph showing the nerve terminal closer to a secretory cell. The basement membrane and some collagen fibres separate the terminal from the cell. Note the two types of vesicles and the mitochondria. $\times 39,000$

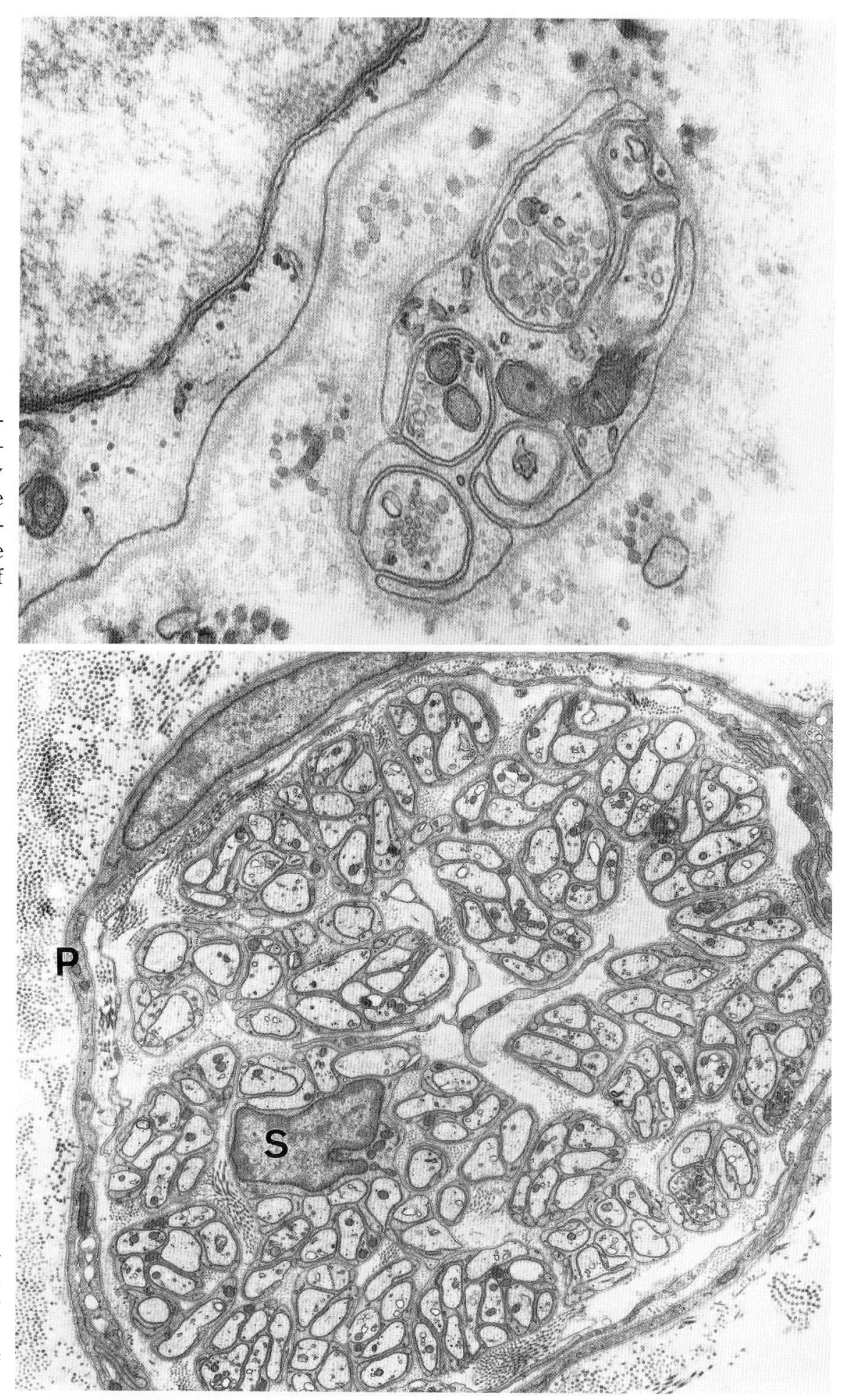

Fig. 12. A nerve bundle in the vicinity of the gland, showing the perineurium $(P)$ and the Schwann cell $(S)$. All the nerve fibres appear to be unmyelinated. $\times 3,900$ 

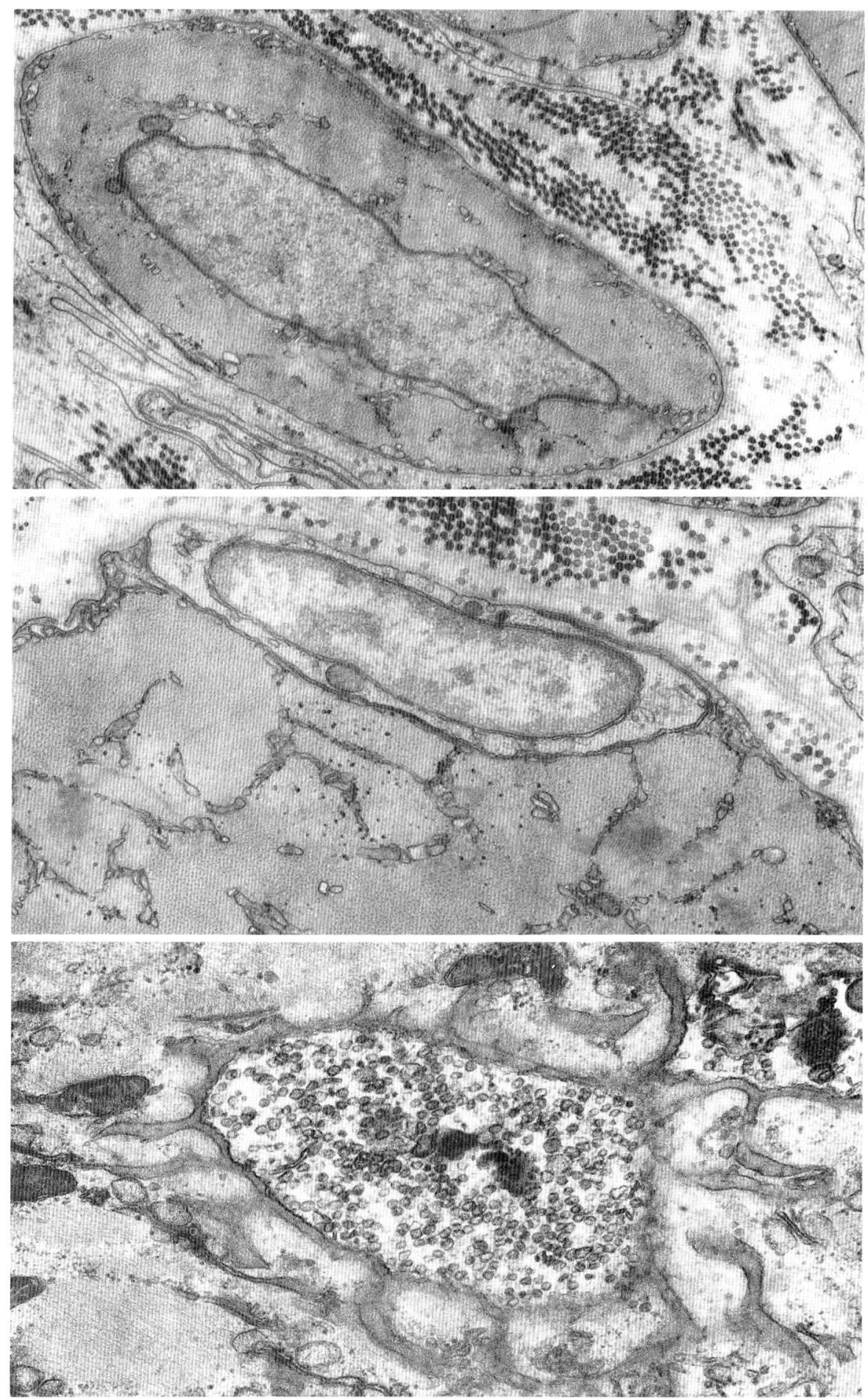

Fig. 13. A cross section of a single muscle fibre from the muscle surrounding the venom gland. The nucleus is centrally placed. Sarcolemmal membrane and basement membrane are clearly seen. $\times 18,000$

Fig. 14. A section of a muscle fibre showing the satellite cell. The muscle fibre shows thick and thin filaments cut in cross section, the sarcoplasmic reticulum and the transverse tubules. The satellite cell shows a large nucleus with minimal cytoplasm and a few mitochondria. Note that the satellite cell is outside the sarcolemmal membrane but inside the basement membrane. $\times 24,000$

Fig. 15. The appearance of a neuromuscular junction in the skeletal muscle. The presynaptic portion shows numerous pleomorphic vesicles, and the post synaptic portion shows numerous folds. $\times 27,500$ 
thread-like fine filaments were also seen in the cytoplasm.

Nerve terminals were seen closer to the base of the secretory cells, but outside the basement membrane. Though the terminals showed pleomorphic vesicles with variations in size, shape and electron density, two types were generally common and could be easily identified (Fig. 11). The first type was the large, rounded and electron dense vesicles; the second was small, rounded and translucent vesicles. The nerve bundles which were seen much closer to the gland substance showed an endoneural lining the fibres, which appeared mostly unmyelinated with a few collagen fibres in between (Fig. 12).

The compressor muscle of the gland when examined with the electron microscope showed fibres which were arranged separately, with intervening collagen fibres and fibroblasts. The sarcolemmal membrane was clearly definable. The characteristic features such as the dark $\mathrm{A}$ band, the light I band and the $Z$ disc, in addition to the $\mathrm{H}$ zone, were visible in certain regions. Mitochondria were seen scattered between the myo- filaments and glycogen granules. A triad consisting of the transverse tubule and the sarcoplasmic reticulum was present. The sarcoplasmic reticulum appeared to be considerably branched. The nucleus of the muscle fiber was situated in the centre of the fiber (Fig. 13). Satallite cells were seen situated in the periphery of the individual muscle fiber. They were spindles or half moons in shape, situated outside the sarcolemmal membrane, but inside the basement membrane (Fig. 14). The nuclei of the satellite cells were of larger size in comparison to the amount of cytoplasm. The cytoplasm showed a few mitochondria and some other organelles.

The neuromuscular junctions which were seen in relation to the compressor muscle showed the presynaptic as well as the post-synaptic portions. The presynaptic portion showed a large number of regular translucent clear vesicles with a few mitochondria scattered between them. There was a regular electron dense synaptic gap between the presynaptic and postsynaptic membrane. The postsynaptic membrane was thrown into folds (Fig. 15).

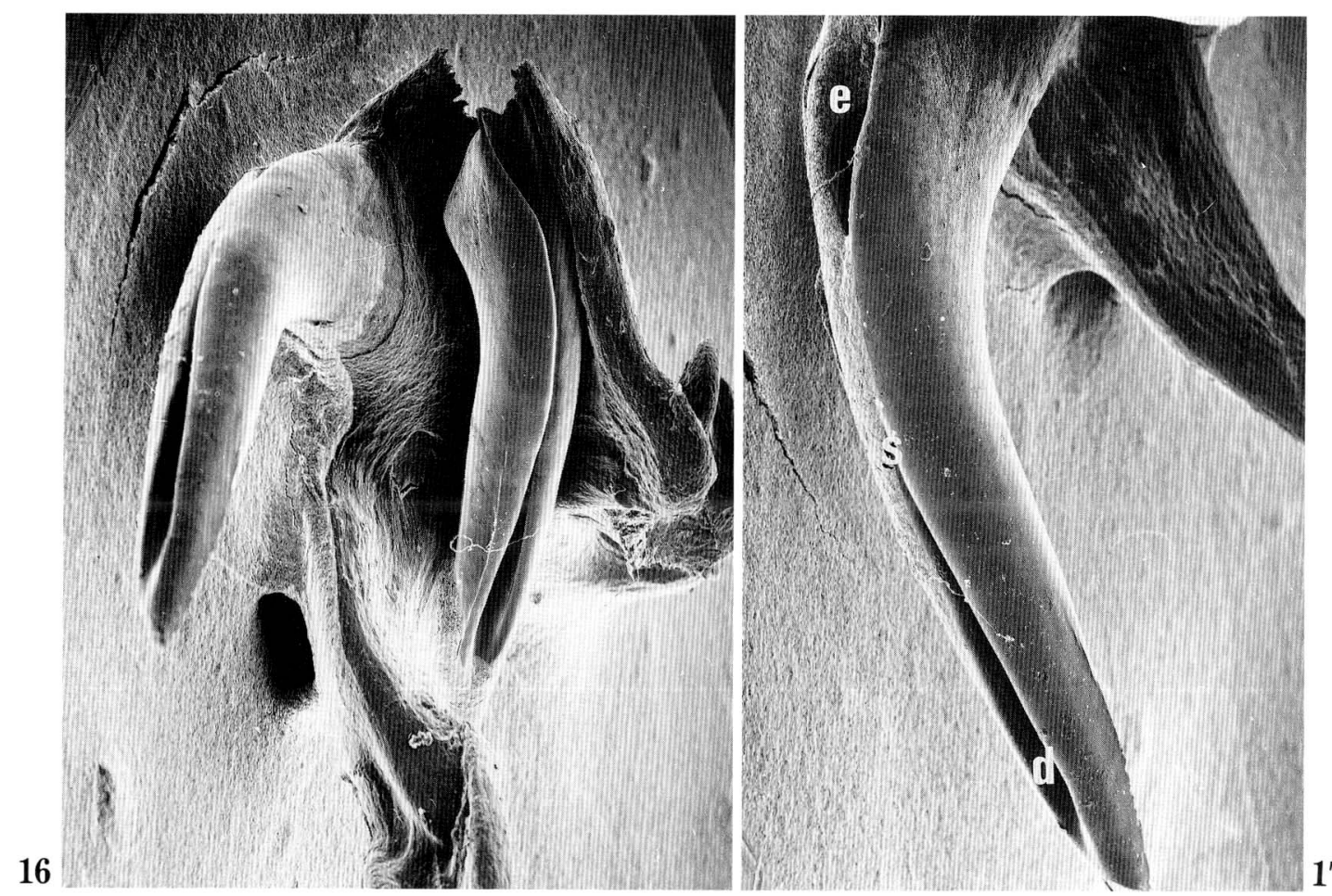

Fig. 16. Scanning electron micrograph showing two fangs of the blue coral snake attached to the right maxilla. $\times 48$

Fig. 17. SEM of a single functional fang showing the entrance lumen $(e)$, discharge orifice $(d)$, and the suture $(s) . \times 52$ 
Those blood vessels which were closely related to the gland showed a smooth muscle layer and endothelial cell layer. The endothelial cells showed electron dense bodies in the cytoplasm. The cytoplasm of the endothelial cells displayed wavy extensions into the lumen of the blood vessels.

There were two fangs on each maxillary bone. SEM showed that the fangs appeared to be grooved on the anterior aspect. The groove was fused only along a small portion (about 1/5th of the whole length) at the junction between the upper $1 / 5$ to lower $3 / 5$. The venom duct opened into a heart shaped opening situated on the anterior aspect of the upper $1 / 5 \mathrm{~m}$ of the fang. The discharging orifice occupied the lower $3 / 5$ of the anterior surface of the fang and appeared like a long spindle. On either side of the tip of the fang, both laterally and medially, there were two sharp dental ridges. The sharp ridge from the lateral side continued to the tip of the fang and then on to the medial side (Figs. 16, 17).

\section{DISCUSSION}

The blue coral snake (Maticora bivirgata) appears to have the longest venom gland among snakes. There are other snakes which have extended or elongated venom glands, such as the banded coral snake (Maticora intestinalis) (GOPALAKRISHNAKONE, 1986). Viperids of the genus Causus, such as $C$. resimus and C. rhambeatus have also revealed posteriorly extended venom glands (HAAS, 1952). Of the genus Atractaspis, engaddenis and some other species also showed an extended venom gland (KocHVA, 1959; KocHVA et al., 1967). Although these snakes possessed extended venom glands, there were many differences among them, e.g., in their extent, morphology, arrangement of muscle and the presence of accessory glands.

Serial sections and light microscopy revealed that the $M$. compressor glandulae of the venom gland in Maticora was attached entirely to the main venom gland and extended slightly into the duct region. There were no other attachments to any bony structures. This is different from the $A$. engaddensis compressor muscle which originates from the head of the quadrate and Harder's gland (KoCHVA, 1962). In transverse sections of the gland in $A$. engaddensis, the muscle could be seen in two portions-one dersal and one ventral-whereas in $M$. bivirgata, the muscle fibres were arranged circumferentially, surrounding the venom gland uniformly. The other feature for $A$. engaddensis: was the absence of a well developed epimysium, perimysium or endomysium. Such was also the case with $A$. engaddensis, although have the gland and its enveloping muscle lay free and uncovered (except by the skin) in a shallow depression of the lateral body muscles (KocHVA, 1959). In the case of $M$. bivirgata, the gland extended into the coelomic cavity and the muscle fibre arrangement seemed to differ from $A$. engaddensis. However, the absence of a well developed epimysium, perimysium and endomysium in both cases seems to suggest that the emptying of this long extended venom gland by the contraction of the muscle might provide the answer. KochVA (1959) observed in A. engaddensis that the gland and compressor muscle on the left side was longer and was twisted around its long axis. In comparison, $M$. bivirgata (present study) or $M$. intestinalis (COPALAKRISHNAKONE, 1986) did not show any twisting of the glands, but in all cases the left glands appeared to be longer than those on the right side.

Electron microscopy of the muscle showed structures similar to those related to venom glands as described previously in the banded coral snake $M$. intestinalis (GOPALAKRISHNAKONE, 1986) and the cobra (Naja naja) (GOPALAKRISHNAKONE and JAYATILAKA, 1978).

The main venom gland of $M$. bivirgata appears to be a simple, branched tubular gland without a lumen, whereas that of $A$. engaddensis consists of a large number of radial tubules surrounding a central lumen (KochVA et al., 1967). The PAS reaction did not show many mucous secreting cells in the main gland, although there were a few along the duct. In the case of $A$. engaddensis, the luminal end of the tubules consisted of a mucous epithelium (KocHVA et al., 1967).

The electron microscope revealed features of the main secretory cell and epithelium to be similar to those of a protein secreting gland. The various stages or cycles of cells depending on the stage of milking (KochVA, 1987) could be clearly observed in the epithelium, though no clear cut electron dense granules were present. The secretory granules were either lightly electron dense, or only a part of the vacuole was electron dense.

In previous studies of different species, such as the South American rattlesnake Crotalus durissus terrificus, three cell types were established: the horizontal cell, mitochondria-rich cell and columnar secretory cell (WARSHAWSKY et al., 1973). In the cottonmouth moccasin Ancistrodon p. piscivorus, there were five types of cells: the principal cell, the horizontal cell, mitochondria-rich cell and two lesser common types (ODOR, 1965). The secretory cell of $M$. bivirgata corresponds to the columnar secretory cell 
of $C . d$. terrificus and the principal cell of Ancistrodon p. piscivorus. The horizontal and basal cells are similar in all three species. In the main venom gland, three types of cells were observed in the secretory epithelium, namely the secretory cell, dark cell and the horizontal (basal) cell.

The dark cell of the $M$. bivirgata appears to be a different type of cell from the types of cells described so far. However, WARSHAWSKY et al. (1973) mentions an infrequent type of "dark cell" among the columnar secretory cells of the South American rattlesnake. The lack of a large amount of secretory granules such as the zymogen granules in the cytoplasm of the secretory cell-is a subject of much debate (ODOR, 1965; GENNARO et al., 1960, 1963; WARSHAWSKY et al., 1973). The large vacuoles or some vacuoles or cavities with dense intracavity material may contain the venom secretion; this has been supported in $C$. $d$. terrificus by radioautographic studies (WARSHAWSKY et al., 1973). Horizontal cells or basal cells have been described by KOCHVA and GANS (1965), ODOR (1965), WARSHAWSKY et al., 1973, GOPALAKRISHNAKONE, $1985 \mathrm{a}, 1986)$ in various snake venom glands. There has been discussion by these authors on the functions of these cells as to whether they are myoepithelial cells or embryonic cells with the potential to differentiate into secretory cells. No condclusive statement as to the exact functions of these cells was arrived at; however, when tese cells were examined under higher EM magnification, they did show some fibrils similar to myofibrils.

The innervation of the venom glands of snakes (e. g., Vipera palaestinae) has been described in gross anatomical terms (KochVA and GANS, 1965) but in this study we have demonstrated the structure of the nerve terminal supplying the secretory cell at the EM level. The presence of two types of vesicles is indicative of two types of neurotransmitters. The blood vessels were studied in detail because of the finding of so many in the gland and also because of large blood vessels seen inside the capsule in relation to secretory tubules. The study was carried out the purpose of looking for any evidence of any endocrine activity or endocrine cells in the venom gland. Our observations showed that there were no endocrine cells or any transport of material from the secretory or any other cells into the blood vessel.

Scanning electron microscopy of the fangs of $M$. bivirgata revealed basic features such as the entrance lumen, discharge orifice and the suture, which were similar to the fangs of $M$. intestinalis (GOPALAKRISH NAKONE, 1986), Dispholidus typus and Thelotornus kirtlandii (MEIER, 1981), Atractaspis engaddensis (Ko.
CHVA and MEIER, 1986) spitting cobras (GOPALAKRISHNAKONE and KOCHVA, 1989a) and sea snakes (GOPALAKRISHNAKONE and KOCHVA, 1989b). There were, however, many differences in the shape of the entrance lumen, the shape of the discharge orifice, the length of the suture line in comparison to the total length of the fang and also the presence of dental ridges or sharp edges in relation to the tip of the fang. The fang of $M$. bivirgata showed the dental ridge on the medial and lateral sides of the fang, interconnected across the tip like a sharp cutting blade; this ridge extended along the whole length of the discharging orifice. In the case of $N$. n. sputatrix, the fang also showed dental ridges on either side, but they did not cover the entire length of the discharging orifice (GOPALAKRISHNAKONE and KOCHVA, 1989a) whereas in the sea snakes (e.g. Lapermis hardwicki) there were no prominent dental ridges but rather, hairline markings on either side of the fang which sometime ran throughout the entire length of the fang (GOPALAKRISHNAKONE, 1986; GOPALAKRISHNAKONE and KOCHVA, 1989b). In comparison, Rhamphiophis oxyrhynchus and Dispholidus typus revealed blade-like dental ridges at the front side of the apex (MEIER, 1981), whereas the fangs of Atractaspis engaddensis showed the dental ridge protruding from the surface of the fang at its posterior.

\section{REFERENCES}

BDolah, A.: The venom gland of snakes and venom secretion. In: (ed. by) C. Y. LEE: Snake venoms. Springer-Verlag, Berlin-Heidelberg-New York, 1979 (p. 41-57).

Ben-Shaul, Y., S. Lifshitz and E. KochVa: Ultrastructural aspects of secretion in the venom glands of Vipera palaestinae. In: (ed. by) P. RossenBERG: Toxins of animal and plant origin, Vol. 1. Pergamon Press, Oxford-New York-London, Gordon and Breach, 1971 (p. 87-105).

Burns, B. and G. V. Pickwell: Cephalic glands in seasnakes (Pelamis, Hydrophis and Laticauda). Copeia 3: 547-559 (1972).

Gans, C. and E. Kochva: The accessory gland in the venom apparatus of viperid snakes. Toxicon $3: 61-63$ (1965).

Gennaro, J. F. Jr., W. P. Callahan, III and A. F. LoRINCZ: The anatomy and biochemistry of a mucus secreting cell type present in the poison apparatus of the pit viper, Ancistrodon piscivorus piscivorus. Ann. New York Acad. Sci. 106: 463-471 (1963). 
Gennaro, J. F. Jr., P. J. Squicciarini, M. Heisler and H. P. Hall: The microscopic anatomy and histochemistry of the poison apparatus of the cottonmouth moccasin, Ancistrodon p. piscivorus. Anat. Rec. 136: 196 (1960).

Gopalakrishnakone, P.: Light and electron microscopic study of the venom apparatus of the saw-scaled viper Echis carinatus. Snake 17: 10-14 (1985a).

: Structure of the venom glands of sea snakes (Hydrophidae). Toxicon 23(4): 571 (1985b).

- Structure of the venom gland of the Malayan banded coral snake Maticora intestinalis. Snake 18: 1926 (1986).

Gopalakrishnakone, P. and A. D. P. Jayatilaka: An electron microscopic study of the adductor externus superficialis muscle associated with the venom gland of the cobra (Naja naja). J. Anat. 126: 59-63 (1978).

GopalakrishnaKone, P. and E. KochVa: Functional anatomy of the venom apparatus of spitting cobras. Toxicon 27: 48 (1989a).

- 1 : Morphology of the venom glands of fourteen species of sea snakes from the South China Sea and the Straits of Malacca. Toxicon 27: 48 (1989b).

HAAS, G.: The head muscles of the genus ausus (Ophidia, Solenoglypha) and some remarks on the origin of Solenoglypha. Proc. Zool. Soc. Land. 122: 573-592 (1952).

JaYATILAKa, A. D. P. and P. Gopalakrishnakone: A histological study of the venom apparatus of the cobra (Naja naja) and of Hump-nosed viper (Agkistrodon hypnale) of Sri Lanka. Ceylon. J. Sci. (Biosci.) 14: 19-40 (1981).

Kochva, E: On the lateral jaw musculature of the Solenoglypha with remarks on some other snakes. J. Morphol. 110: 227-284 (1962).

-: Phylogeny of the oral glands in reptiles as related to the origin and evolution of snakes. In: (ed. by) P. RosenberG: Toxins: animal, plant and microbial. Pergamon Press, Oxford-New York, 1978a (p. 29-37). : Oral glands of the Reptilia. In: (ed. by) C. GANS and K. A. Gans: Biology of Reptilia, Vol. 8. Academic Press, London and New York, 1978b (p. 43-161).

: The origin of snakes and evolution of the venom apparatus. Toxicon 25(1): 65-106 (1987).
Kochva, E. and C. Gans: The venom gland of Vipera palaestinae with comments on the glands of some other viperines. Acta Anat. (Basel) 62: 365-401 (1965). : Histology and histochemistry of venom glands of some crotaline snakes. Copeia 1966: 506-515 (1966).

The structure of the venom gland and secretion of venom in viperid snakes. In: (ed. by) $F$. E. Russell and P. R. SAunders: Animal toxins. Pergamon Press, Oxford-New York, 1967 (p. 195-203).

Kochva, E. and J. Meier: The fangs of Atractaspis engaddensis Haas Rev. Suisse Zool. 93: 749-754 (1986).

Kochva, E., M. Shayer-Wollberg and R. Sobol: The special pattern of the venom gland in Atractaspsis and its bearing on the taxonomic status of the genus. Copeia 1967: 763-772 (1967).

MEIER, J.: The fangs of Dispholidus typus Smith and Thelotornis kirtlandii Smith. Rev. Suisse Zool. 88: 897902 (1981).

Odor, D. L.: The poison gland of the cottonmouth moccasin, Ancistrodon p. piscivorus as observed with the electron microscope. J. Morphol. 117: 115-134 (1965).

W arshawsky, H., A. Haddad, R. P. Gocalve, V. VALERI and F. L. DE LuCCA: Fine structure of the venom gland epithelium of the South American rattlesnake and radioautographic studies of protein formation by the secretroy cells. Amer. J. Anat. 138: 79-120 (1973).
Dr. P. GOPALAKRISHNAKONE Department of Anatomy Faculty of Medicine National University of Singapore Singapore 0511 